OPEN ACCESS

Edited by:

Xiaoshan Wu,

Central South University, China

Reviewed by:

Nan Jiang,

Peking University Hospital of Stomatology, China

Xiaoxing Kou,

Sun Yat-sen University, China

*Correspondence:

Yan Xu

yanxu@njmu.edu.cn

Jinhua Yu

yujinhua@njmu.edu.cn

Specialty section:

This article was submitted to

Regenerative Dentistry,

a section of the journal

Frontiers in Dental Medicine

Received: 22 October 2021 Accepted: 29 November 2021 Published: 16 December 2021

Citation:

Ye Y, Zhao X, Xu Y and Yu J (2021) Hypoxia-Inducible Non-coding RNAs in Mesenchymal Stem Cell Fate and Regeneration

Front. Dent. Med. 2:799716. doi: 10.3389/fdmed.2021.799716

\section{Hypoxia-Inducible Non-coding RNAs in Mesenchymal Stem Cell Fate and Regeneration}

\author{
Yu Ye ${ }^{1,2}$, Xinyuan Zhao ${ }^{1,3}$, Yan $X u^{1,4 *}$ and Jinhua Yu ${ }^{1,2 *}$ \\ ${ }^{1}$ Key Laboratory of Oral Diseases of Jiangsu Province, Stomatological Institute, Nanjing Medical University, Nanjing, China, \\ ${ }^{2}$ Endodontic Department, School of Stomatology, Nanjing Medical University, Nanjing, China, ${ }^{3}$ Stomatological Hospital, \\ Southern Medical University, Guangzhou, China, ${ }^{4}$ Periodontics Department, School of Stomatology, Nanjing Medical \\ University, Nanjing, China
}

Mesenchymal stem cells (MSCs) can differentiate into multiple cell lines, which makes them an important source of cells for tissue engineering applications. They are defined by the capability to renew themselves and maintain pluripotency. This ability is modulated by the balance between complex cues from cellular microenvironment. Self-renewal and differentiation abilities are regulated by particular microenvironmental signals. Oxygen is considered to be an important part of cell microenvironment, which not only acts as a metabolic substrate but also a signal molecule. It has been proved that MSCs are hypoxic in the physiological environment. Signals from MSCs' microenvironment or niche which means the anatomical location of the MSCs, maintain the final properties of MSCs. Physiological conditions like oxygen tension are deemed to be a significant part of the mesenchymal stem cell niche, and have been proved to be involved in modulating embryonic and adult MSCs. Non-coding RNAs (ncRNAs), which play a key role in cell signal transduction, transcription and translation of genes, have been widely concerned as epigenetic regulators in a great deal of tissues. With the rapid development of bioinformatics analysis tools and high-throughput RNA sequencing technology, more and more evidences show that ncRNAs play a key role in tissue regeneration. It shows potential as a biomarker of MSC differentiation. In this paper, we reviewed the physiological correlation of hypoxia as a unique environmental parameter which is conducive to MSC expansion and maintenance, discussed the correlation of tissue engineering, and summarized the influence of hypoxia related ncRNAs on MSCs' fate and regeneration. This review will provide reference for future research of MSCs' regeneration.

Keywords: hypoxia, mesenchymal stem cell, non-coding RNA, differentiation, niche

\section{INTRODUCTION}

\section{Hypoxia Microenvironment in Mesenchymal Stem Cells}

Mesenchymal stem cells (MSCs) represent a subset of adult stem cells derived from the mesoderm lineage. The identification standard established by the International Society for Cell Therapy (ISCT) is to prove the positive expression characteristics of CD73, D90 and CD105, and lack of expression of CD14, CD34, CD45, and human leukocyte antigen-DR (HLA-DR) $(1,2)$. As non-hematopoietic 
progenitor cells, MSCs can be obtained from a variety of human tissues, which include bone marrow, adipose tissue, skin and dental pulp, etc $(3,4)$. Multiple tissue cells derived from the mesoderm and neuroectoderm can be differentiated by MSCs, such as bone marrow stromal cells (BMSCs), fibroblasts, osteoblasts, chondrocytes, adipocytes, and vascular endothelial cells, even neurons and glial cells of the nervous system (5-7).

MSCs in vivo help maintain and regulate the homeostasis of related organs, and the modification or transplantation of MSCs seems to be the preferred treatment method in a variety of pathological processes (8). Specifically, stem cells are life-long reservoirs of several cell types, which have the characteristics of fighting inflammation and other diseases. Hence, MSCs have been used as the most practical stem cells in the treatment of different systemic diseases (9).

Stem cells and their precursors exist in the stem cell niche (10), which is a particular cell microenvironment. Several recent literatures suggest in the stem cell niche, hypoxia environment plays a key role for keeping the phenotype of precursor cells and undifferentiated stem cells (11). Hypoxia helps stem cells to stay in a quiescent status and has the necessary self-renewal rate. The response of stem cells to hypoxia is one of the main mechanisms for adapting to changes in the external and internal environment. It has been observed for decades that stem cells can respond immediately to hypoxia (12). Recent findings have shown that hypoxia not only induces the proliferation of several stem cells in vitro, but also participates in stem cells differentiation and survive $(13,14)$.

Inflammation and malignant tumors all present hypoxic environment, and bone reconstruction under physiological condition is also strictly controlled by signaling pathways related to hypoxia. The physiological bone reconstruction might be caused by the hypoxic environment of the bone cell niche (15). Studies in mice show that the lowest oxygen tension is $1.3 \mathrm{kPa}$ (10 mmHg; tissues lower than this level are commonly known as hypoxic tissues) $(16,17)$. Mammalian adaptation to hypoxia at the cellular and systemic levels is mainly provided by the transcription regulator hypoxia inducible factor (HIF). HIFs are heterodimeric transcription factors, including a $\alpha$ subunit (HIF$1 \alpha$, HIF- $2 \alpha$, HIF- $3 \alpha$ ) and a composition $\beta$ subunit (HIF- $\beta$ ) which is vital in inducing the response of cells to hypoxia $(18,19)$. HIF1- $\alpha$ and HIF2- $\alpha$ are similar in structure (20). The stability of these molecules is dominated by the oxygen availability through the iron-dependent enzyme prolyl hydroxylase (PHDs) after transcription (21).

Different oxygen pressure and hypoxia exposure time may play important and different roles in cell development. Effects of hypoxia on the influences of MSCs of literature were shown in Table 1. Transcription factors and cytokines obviously affect these processes. Studies have proved that factors which regulate the behavior of stem cells and progenitor cells have an important relation with HIFs. The HIFs act as a molecular framework for hypoxia to control differentiation and survival of cells (43). Hypoxia is by no means a purely pathological state. Hypoxia often occurs under various physiological conditions, especially when rapid tissue growth lags behind the development of blood supply. First, it is related to embryogenesis under $1-5 \%$ oxygen content. However, this situation is not harmful to normal embryonic development; moreover, it seems to be an indispensable and completely "selected" one in the evolutionary process of mammalian embryo formation. This may indicate that under hypoxic conditions, all developing tissues have regular relationships (10).

In some aspect, hypoxia is thought to be the better environment for the maintenance and function of various stem cell types (such as embryos, hematopoiesis, mesenchymal and neurons). It promotes stem cells to remain at rest at the necessary rate of self-renewal. There is a certain regulatory mechanism to maintain hypoxic state in stem cell niche. This microenvironment basically affects the proliferation and differentiation ability of stem cells and protects cells against the toxicity and mutagenicity of oxygen free radicals. The key element of these mechanisms is HIF, a complex of hypoxia inducible transcription factors (10).

Under hypoxia condition, HIF complexes can induce Notch signaling by attaching to Notch receptors (44). Notch signal plays a key role in the determination of cell survival. Notch signal induced by HIF has been proved to be related to the determination of stem cell fate. In relative studies, hypoxia and HIFs have been shown to be involved in osteogenesis, cartilage formation, angiogenesis, heart formation and the formation of neural crest $(34,45-47)$. With the introduction of new technologies into this field, the development of single cell RNA sequencing, transcriptome sequencing and material technology, recent researches have vividly described some epigenetic changes, including hydroxy methylation, histone modification, DNA methylation, organ like and three-dimensional structure formation in early embryonic development, induced pluripotent stem cells (iPSCs) and somatic reprogramming. The interaction between hypoxia and epigenetics has potential application in regenerative medicine (48). Hypoxia can affect the level of epigenetic modification of cells. The coexistence of transcription factors suggests that hypoxia may have a relation with epigenetics in cell reprogramming regulation (48).

It is undeniable that HIF signaling and epigenetics are involved in the events that lead to stem cell proliferation and differentiation. The review may help deepen the understanding of tissue regeneration microenvironment.

\section{Non-coding RNAs}

Non-coding RNAs (ncRNAs) are molecules that have no or very low ability to code protein. In fact, although most human genes can be transcribed into RNAs, some of the RNAs cannot be translated into proteins (49). Recently, with the progress of multidisciplinary methods and high-throughput technologies, we begin to know more about ncRNAs and its' signaling network. Generally speaking, ncRNAs are found to be involved in a variety of biological processes, regulating physiological and developmental processes and even diseases.

Based on different regulatory effects, ncRNAs are generally divided into two categories. Housekeeping ncRNAs are widely expressed in cells and mainly modulate the general function of cells. Although regulatory ncRNAs are generally regarded 
TABLE 1 | Effects of Hypoxia on the influences of MSCs.

\begin{tabular}{|c|c|c|c|}
\hline MSCs types & Oxygen concentration & Influences & References \\
\hline Human bone marrow-derived & $1 \%$ & Induce migration and angiogenesis & $(22)$ \\
\hline Human dental pulp & $1 \%$ & Enhance the angiogenic potential & $(23)$ \\
\hline Human bone marrow-derived & $5 \%$ & Enhance clonogenicity but impair differentiation & $(24)$ \\
\hline Human bone marrow-derived & $2 \%$ & Induce osteogenic differentiation & $(25)$ \\
\hline Human bone marrow-derived & $3 \%$ & Inhibit osteogenic differentiation and enhances stemness & $(26)$ \\
\hline Rat bone marrow-derived & $1 \%$ & Regulate the osteogenesisin a time-dependent manner & $(27)$ \\
\hline Human dental pulp & $1 \%$ & Accelerate bone healing & $(28)$ \\
\hline Human bone marrow-derived & $1 \%$ & Induction of adipocyte-like phenotype & (29) \\
\hline Human bone marrow-derived & $2 \%$ & Enhance proliferation and tissue formation & (30) \\
\hline Placental-derived & $5 \%$ & Promote osteogenesis & (31) \\
\hline Human bone marrow-derived & $1 \%$ & Reduce proliferation and differentiation & $(32)$ \\
\hline Human urine/dental pulp/amniotic fluid & $5 \%$ & $\begin{array}{l}\text { Enhance cell proliferation rate, retention of stem cell } \\
\text { properties, inhibition of senescence, and increased } \\
\text { differentiation ability }\end{array}$ & (33) \\
\hline Human bone marrow-derived & $1 \%$ & Enhance chondrogenesis & (34) \\
\hline Rat bone marrow-derived & $5 \%$ & Enhance osteochondrogenesis & (35) \\
\hline Human dental pulp & $5 \%$ & Promote mineralization & (36) \\
\hline Murine bone marrow & $1 \%$ & Promote the progression of the chondrocyte lineage & $(37)$ \\
\hline Human apical papilla & $1 \%$ & Promotes osteogenic and neurogenic lineages & (38) \\
\hline Human periodontal ligament & $2 \%$ & Induce osteogenesis and angiogenesis & (39) \\
\hline Human bone marrow-derived & $1 \%$ & Increase chemotaxis migration & $(40)$ \\
\hline Human bone marrow-derived & $2 \%$ & Reduce osteogenic differentiation & $(41)$ \\
\hline Human periodontal ligament & $2 \%$ & Enhance osteogenic differentiation & $(42)$ \\
\hline
\end{tabular}

as significant RNA molecules, they play a regulatory role in gene expression at the epigenetic, transcription and posttranscriptional levels (50-52).

According to the average size of regulatory ncRNAs, they can be farther divided into small ncRNAs containing $<200 \mathrm{nt}$ transcripts and long non-coding RNAs (lncRNAs) larger than 200 nt. Most of small RNAs can be divided into small interfering RNAs (siRNAs), microRNAs (miRNAs) and piwi-interacting RNAs (piRNAs). However, a number of variable-length noncoding RNAs may belong to both categories, like enhancer RNAs, circular RNAs (circRNAs) and promoter-related transcripts (53).

MiRNAs are endogenous, single-strand small ncRNAs and consist of 20-25 nucleotides. With a complex enzymatic pathway, they are usually synthesized from larger RNAs transcripts. MiRNAs can be transcribed into pri-miRNAs by RNA polymerase II or III, or processed from ncRNAs, or processed from introns of protein-coding genes (miRtrons) (54). As the largest type of small non-coding RNAs produced by the transcribed hairpin loop structure $(55,56)$. miRNAs could modulate gene expression in and outside nucleus with different biological mechanisms, and silence gene after transcription (56). As a key participant in the complex interaction between different RNAs species, miRNAs have been widely concerned by researchers in recent years.

LncRNAs refer to transcripts with a length of more than 200 nt and no capabilities to code protein. According to their position relative to genes that code protein, lncRNAs can be divided into five subclasses (57): (1) promoter-related lncRNAs, (2) enhancerrelated lncRNAs, (3) natural antisense transcripts, (4) genomerelated (sense) lncRNAs and (5) long intergenic ncRNAs (58). Based on their regulatory effects on DNA sequences, lncRNAs can be subdivided into trans-lncRNAs (trans-acting lncRNAs) and cis-lncRNAs (cis-acting lncRNAs), the former regulating the expression of close-range genes (59). Some ncRNAs can be farther processed to produce small ncRNAs, like miRNAs (60).

CircRNAs are endogenous circular RNAs with a covalent closed loop structure. Although it has been discovered for many years, circRNAs has recently received further attention with the development of bioinformatics analysis and deep sequencing (61). CircRNAs are mostly formed by the "reverse splicing" of pre-mRNAs and are mainly found in the cytoplasm or exosomes $(62,63)$. These circRNAs are more stable than linear RNAs because they have a special form with a covalent ring instead of linear form, which makes it hard for ribonuclease $\mathrm{R}$ to degrade them (64). CircRNAs can be divided into four types: ciRNAs, ecircRNAs, tricRNAs, EIciRNA, based on the pattern of biogenesis and the source of the genome. The size range of circRNAs is very wide, from $100 \mathrm{nt}$ to more than $10,000 \mathrm{nt}$, and most circRNA in mammals or plants are made of hundreds of nucleotides $(64,65)$. Just like other regulatory non-coding RNAs, circRNAs work in plenty of biological processes, like modulating alternative RNA splicing or transcription (62), acting a competitive role as endogenous RNA (ceRNAs) (66) or miRNA sponges (67). 
Thanks to the rapid development of sequencing technology and bioinformatics methods, in the past few decades, different types of ncRNAs have been found, constructing a complicated ncRNAs system. There is ample evidence that ncRNAs acts an important biological role in regulating cellular mechanisms. They may regulate cell behaviors of stem cells in their niche. In addition, complex microenvironmental factors may also induce a variety of ncRNAs to influence the fate of these cells.

\section{Hypoxia Induced ncRNAs}

Under hypoxia, more than 800 target genes related to different signaling pathways such as apoptosis, proliferation, metabolism and angiogenesis were activated. Hypoxia inducible factor-1 (HIF-1) plays an important role in hypoxia microenvironment as a key mediator (68). HIF-1 complex transcriptionally activates ncRNAs in response to hypoxia. Under normal circumstances, PHDs and other proline hydroxylases hydroxylate the subunits of HIF-1/2 $\alpha$. The von Hippel-Lindau (VHL) protein further recognizes the hydroxylated HIF- $1 / 2 \alpha$ as a target for subsequent ubiquitination and proteasome degradation. Under hypoxic conditions, HIF- $1 / 2 \alpha$ cannot be hydroxylated and gradually accumulates, nuclear translocation, and forms dimers with HIF$\beta$. It forms a transcription initiation complex with the recruited $\mathrm{CBP} / \mathrm{p} 300$ and binds to the promoter of the target gene to induce target gene expression. Hypoxia can induce the expression of ncRNAs. ncRNAs including miRNAs, lncRNAs or circRNAs are involved in regulating cell proliferation, cycle and death and other cell behaviors (Figure 1). Some of them can participate in the regulation of HIFs (69). Such as, lncRNA H19 was found highly expressed under hypoxia and may be involved in regulating stem cell behaviors (70). LncRNA HIF-1 $\alpha$-AS2 facilitates the maintenance of stem cell-like cells in hypoxic niche mesenchymal glioblastoma. The expression of ncRNAs in MSCs was significantly altered under different hypoxia conditions (71). For example, in $0.5 \% \mathrm{O}_{2}$ stimulated BMSCs, 15 common miRNAs (miR-22, miR-29b, miR-214, miR-140-3p, miR-17, miR24, miR-320a, miR-26a, miR-1233, miR-222, miR-193b, miR150 , let-7F, let-7a, and miR-516a-5p) were significantly changed (72). miR-210 is a major hypoxia-induced miRNA in most cells (73). Dental pulp stem cells (DPSCs) showed stronger proliferation and lower osteogenic/odontogenic differentiation potential under hypoxia. Compared with normoxic group, 60 mRNAs (25 up-regulated, 35 down-regulated), 47 lncRNAs (20 increased, 27 decreased) and 14 miRNAs (7 up-regulated, 7 down-regulated) were differentially expressed in DPSCs in hypoxic group. After a bioinformatics analysis, 7 mRNAs of GRPR, ERO1L, ANPEP, EPHX1, PGD, ANGPT1 and NQO1 and 5 lncRNAs of AF085958, AX750575, UC002CZN.2, RP3-413H6.2 and six twelve leukemia (STL) may be associated with each other. twenty eight mRNAs including GYS1, PRKACB and NQO1 and 13 miRNAs including hsa-miR-3916 and hsa-miR-192-5p may be correlated with each other and play roles (74). There were 102 differentially expressed circRNAs in BMSCs under hypoxia $\left(1 \% \mathrm{O}_{2}\right)$ pretreatment. Its function may mainly regulate cell development, differentiation and regulation by affecting gene stability. Transcriptional abnormalities are most prominent in the mitogen-activated protein kinase (MAPK) signaling pathway, which may be the core pathway associated with hypoxia in cells (75).

In the previous study of our group, it was found from highthroughput data that a total of, 1046 mRNAs were differentially expressed in periodontal ligament stem cells (PDLSCs) under hypoxia $\left(2 \% \mathrm{O}_{2}\right)$ and normoxia culture. Compared with normoxia group, 516 mRNAs were up-regulated and 530 were down-regulated under hypoxia. A total of 449 lncRNAs were differentially expressed, of which 406 were increased and 43 decreased in the hypoxia group, and 53 circRNAs were found to be differentially expressed in the hypoxia group, including 17 upregulated and 36 reduced. In addition, 15 miRNAs were found to be differentially expressed in the hypoxia group, of which 6 were increased and 9 were decreased.

\section{Hypoxia Induced ncRNAs With a Role in the Fate of MSCs}

Studies have shown that BMSCs exhibit greater colony-forming potential in hypoxia $(35,76)$, proliferate faster $(77,78)$, and better maintain their undifferentiated properties in hypoxia $(26,30)$. Hypoxia not only affected the differentiation of BMSCs, but the migration ability and survival rate of MSCs in hypoxia preconditioning group were significantly higher than those in normoxia group $(79,80)$. In addition, HIF- $1 \alpha$-mediated SDF1 expression may be the molecular mechanism of this process (40). In the studies of BMSCs, hypoxia induced senescence of MSCs, possibly through changes in intestinal flora (81). However, most studies have shown that hypoxia can inhibit the senescence of BMSCs and help maintain their characteristics $(33,82,83)$. In vivo, transplanted MSCs pretreated with hypoxia show higher survival and tissue protection, and microRNA-326 (miR-326) expression in hypoxic MSCs is significantly higher than that in normoxic MSCs (83). Hypoxia pretreatment can simulate physiological conditions, activate the adaptation process of MSCs under physiological conditions, and improve the niche of MSCs, which is conducive to the successful transplantation of MSCs (84). It was found that hypoxic preconditioning of BMSCs (85) and neural stem cells (NSCs) (86) enhances nerve regeneration and promotes neurological recovery after intracerebral hemorrhage.

As exhibited in Table 1, the results showed that the proliferation and differentiation potential of odontogenic MSCs were changed under hypoxia stimulation. However, the results are uncertain due to differences in cell sources and experimental conditions. Hypoxia has been reported to promote the proliferation of odontogenic stem cells $(36,42,87)$. Although some scholars believe that the proliferation and survival of odontogenic stem cells are not changed or inhibited under hypoxia $(38,88)$. The proliferation of PDLSCs was enhanced in $24 \mathrm{~h}$ under $2 \% \mathrm{O}_{2}$ (39). It was also showed that under different oxygen concentrations $\left(21 \%, 5 \%\right.$, and $\left.1 \% \mathrm{O}_{2}\right)$, the proliferation ability of PDLSCs showed a trend of first increasing and then decreasing under lower oxygen concentrations (89). This indicates that for stem cell proliferation, short-term or mild hypoxia may stimulate the adaptive response of cells and 


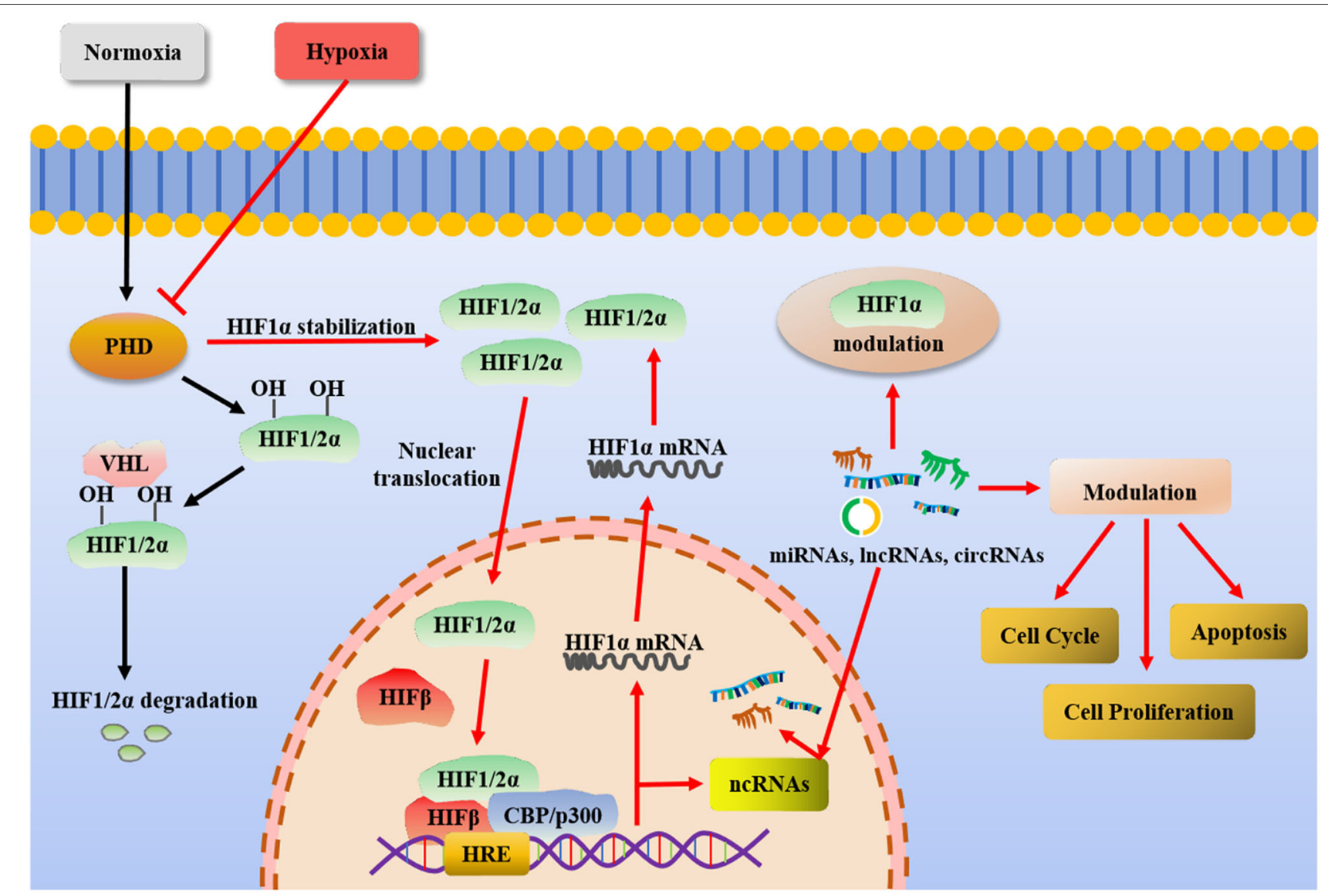

FIGURE 1 | Under normoxia, PHDs and other proline hydroxylases hydroxylate the subunits of HIF-1/2 $\alpha$. The VHL protein further recognizes the hydroxylated $\mathrm{HIF}-1 / 2 \alpha$ as a target for subsequent ubiquitination and proteasome degradation. Under hypoxia, HIF-1/2 $\alpha$ cannot be hydroxylated and gradually accumulates, nuclear translocation, and forms dimers with HIF- $\beta$. It forms a transcription initiation complex with the recruited CBP/p300 and binds to the promoter of the target gene to induce target gene expression. Hypoxia can induce the expression of ncRNAs. ncRNAs including miRNAs, IncRNAs, or circRNAs are involved in regulating cell proliferation, cell cycle and cell death and other cell behaviors.

promote proliferation, while severe or long-term hypoxia may lead to cell death.

Most studies have shown that hypoxia-induced ncRNAs participate in the regulation of migration, proliferation, apoptosis, aging and other survival abilities of different MSCs (Table 2). miR-210 supports the survival of stem cells under hypoxia (96). Ischemia-preconditioning (IP) can improve the survival rate of MSCs under hypoxia, and increase the expression of miR-210. Hypoxia-induced lncRNA H19 expression was negatively correlated with cell injury. Further studies suggested that H19 might activate the Wnt/ $\beta$-catenin and PI3K/AKT pathways by inhibiting the expression of miR-107, and alleviate hypoxia-induced NSC cell damage (97).

It is reported that miR-326 expression is significantly upregulated in hypoxic BMSCS, hypoxic preconditioning upregulates miR-326/PTBP1/PI3K-mediated autophagy (84), LncRNA-P21, HIF-1 $\alpha$, and CXCR4/7 expressions were increased in hypoxic preconditioning induced BMSCs. The migration and viability of MSCs was promoted by P21 under in vitro hypoxic preconditioning (79). DNM3OS/miR-127-5p /GREM2 may be involved in hypoxic chondrocyte differentiation (95). H19 enhanced the survival rate and angiogenesis potential of BMSCs in vitro. It can directly up-regulate VEGFA expression by inhibiting miR-199a-5p as a competitive endogenous RNA (90).

\section{Hypoxia Induced ncRNAs Participating in the Differentiation of MSCs}

Hypoxia stimulation has significant effects on gene expression and is therefore thought to play an important role in early embryonic development, cell reprogramming and differentiation. In general, stem cells show pluripotency and undifferentiated maintenance state under hypoxia (98). Some studies have shown that hypoxia enhances osteogenic/odontogenic differentiation of odontogenic stem cells $(28,88,99)$, while others have reported contrary results (100). Moreover, under severe hypoxia $(0.01 \%$ $\mathrm{O}_{2}$ ) or hypoxia conditions, cell death has been reported to occur (23).

Reduced differentiation of human BMSCs into adipocytes and osteoblasts was found in hypoxic culture (32). However, 
TABLE 2 | Non-coding RNAs involved in regulating the fate and regeneration of MSCs under hypoxia.

\begin{tabular}{|c|c|c|c|c|c|}
\hline ncRNAs & Cell type & $\begin{array}{l}\text { Impact of hypoxia on } \\
\text { ncRNAs expression }\end{array}$ & Effects & Mechanism & References \\
\hline $\begin{array}{l}\text { LncRNA-H19/miR- } \\
\text { 199a-5p }\end{array}$ & Human MSCs & $\begin{array}{l}\text { Up-regulated/down- } \\
\text { regulated }\end{array}$ & $\begin{array}{l}\text { Improve survival and } \\
\text { angiogenic capacity. }\end{array}$ & $\begin{array}{l}\text { VEGFA/miR-199a-5p } \\
\text { axis }\end{array}$ & (90) \\
\hline miR-326 & Human MSCs & Up-regulated & $\begin{array}{l}\text { Delay senescence by } \\
\text { upregulating autophagy }\end{array}$ & PI3K/PTBP1 & (84) \\
\hline LincRNA-p21 & Human MSCs & Up-regulated & $\begin{array}{l}\text { Promote MSC } \\
\text { migration and survival } \\
\text { capacity }\end{array}$ & $\begin{array}{l}\mathrm{HIF}-1 \alpha / \mathrm{CXCR} 4 \text { and } \\
\text { CXCR7 pathway }\end{array}$ & (79) \\
\hline miR-210 & Human MSCs & Up-regulated & Increase survival rates & $\begin{array}{l}\text { HIF-1 } \alpha / A k t / E R K \\
\text { pathway }\end{array}$ & (91) \\
\hline $\begin{array}{l}\text { LncRNA-UCA1/miR- } \\
873-5 p\end{array}$ & Human MSCs & $\begin{array}{l}\text { Up-regulated/down- } \\
\text { regulated }\end{array}$ & $\begin{array}{l}\text { Antiapoptotic and } \\
\text { therapeutic effects }\end{array}$ & miR-873-5p/XIAP axis & (92) \\
\hline miRNA-21 & Human MSCs & Up-regulated & $\begin{array}{l}\text { Promote maxillofacial } \\
\text { bone regeneration }\end{array}$ & PTEN/PI3K/Akt/HIF-1 $\alpha$ & (93) \\
\hline CircCDK8 & PDLSCs & Up-regulated & $\begin{array}{l}\text { Repress the osteogenic } \\
\text { differentiation }\end{array}$ & ER stress/autophagy & (94) \\
\hline $\begin{array}{l}\text { LncRNA } \\
\text { DNM3OS/miR-127-5p }\end{array}$ & Rat MSCs & $\begin{array}{l}\text { Up-regulated/down- } \\
\text { regulated }\end{array}$ & $\begin{array}{l}\text { Inhibit chondrogenic } \\
\text { differentiation }\end{array}$ & $\begin{array}{l}\text { DNM3OS/miR-127- } \\
5 \mathrm{p} / \mathrm{GREM} 2 \\
\text { axis }\end{array}$ & (95) \\
\hline
\end{tabular}

studies were shown that the differentiation ability of BMSCs is reduced under hypoxia compared with normoxia, supporting the idea that hypoxic condition promotes the undifferentiated state of BMSCs $(26,101)$. In conclusion, oxygen tension is an important factor affecting cell fate and regulating cell state. The expressions of OCT-4 and REX-1 are increased in human MSCs under chronic hypoxia $\left(2 \% \mathrm{O}_{2}\right)$ and enhances colony forming unit-fibroblast (CFU-F) capacity while preserving their ability to differentiate into osteoblasts or adipogenic (76).

Hypoxia $\left(3 \% \mathrm{O}_{2}\right)$ was also used to isolate marrow-isolated adult multilineage inducible (MIAMI) cell populations from pluripotent human bone marrow (102). Hypoxia affects the differentiation characteristics of BMSCs, which may be related to the physiological oxygen demand of differentiated cells. It was found that hypoxia enhanced in vitro and in vivo osteogenic potential of rat MSCs (35), while inhibited in vitro osteogenic potential of MIAMI cells (26), and down-regulate osteogenic genes in vitro (103). The angiogenic ability of mouse MSCs was enhanced under $2 \% \mathrm{O}_{2}(22)$, and the expression levels of chondrogenic markers SOX-9, aggregative proteoglycan and Col IIa were increased under $1 \% \mathrm{O}_{2}(37)$. Hypoxia $\left(1 \% \mathrm{O}_{2}\right)$ for $24 \mathrm{~h}$ induced the formation of lipid droplets in human MSCs, but did not up-regulate the expression of adipocyte genes (29).

Numerous studies have shown that miR-210 promotes cell differentiation. Hypoxia-induced miR-210 may promote osteoblast differentiation by inhibiting ACVR1B-Smad 2/3 and activating Smad 1/5/8 (104). Hypoxic-associated miR21 promotes angiogenesis of human umbilical cord blood derived MSCs (UCBMSCs). miR-21 has been demonstrated to promote osteogenesis and enhance osteogenic regeneration of critical size defects through the PTEN/PI3K/Akt/HIF-1 $\alpha$ pathway (93). LncRNA UCA1 of MSCs derived exon plays a protective role through miR-873-5P/XIAP axis in hypoxia (92). CircCDK8 inhibits PDLSCs osteogenic differentiation by triggering autophagy activation in hypoxic microenvironment (94). The relevant ncRNAs involved in regulating the fate and regeneration of MSCs under hypoxia were listed in Table 2.

\section{DISCUSSIONS}

One of the striking features of mammalian development and of human physiological and pathological conditions is hypoxiamediated regulation of stem cell fate, or a decline in oxygen utilization. Therefore, oxygen sensing is necessary because it allows cells to instantly adapt to inadequate amounts of potassium dihydrogen phosphate. HIF is the main regulatory mechanism. In addition, there is increasing evidence that the hypoxic microenvironment is the niche of most types of stem cells, which may be beneficial for stem cell maintenance and the continued replacement of dead or damaged cells in body tissues (105).

The optimal oxygen concentration for stimulating differentiation and survival of stem cells is uncertain and may be influenced by other culture conditions (69). Physiologically normoxic oxygen is considered hypoxic because there is a conserved molecular reaction in the oxygen tension range of 2-9\%. Molecular channels that may be involved include HIF, oxygen ion channel, rapamycin target (mTOR) and endoplasmic reticulum stress response (106-108). As important regulators of stem cell dryness, Oct4 and Notch signals have also been confirmed to be activated by hypoxia in a variety of stem cells (109). Other studies have shown that different degrees of hypoxia have different effects on the proliferation and differentiation of stem cells, suggesting that the proliferation or stasis of stem cells can be regulated by the oxygen concentration of local ecological niche. For example, proliferation of ESCs is inhibited and differentiation increases at oxygen concentrations 
as low as $1 \%$, while pluripotency of ESCs is maintained at $3 \%-5 \%$ oxygen tension without significant change in proliferation (110).

Hypoxia and epigenetic interactions have potential applications in regenerative medicine. It is reported that reprogramming cells exist in many different types of tissues and organs after hypoxia $(111,112)$. Studies have shown that hypoxic environment may contribute to or regulate the process of tissue regeneration. Phenomena such as conditional ischemia caused by hypoxia stimulation can provide attractive prospects for future research (113-115).

As a key factor in determining the characteristics of BMSCs, the microenvironmental niche could maintain and regulate their function. Cell growth and differentiation require a certain amount of oxygen. However, under some physiological and pathological conditions, hypoxia is common. Under extreme hypoxia, the oxygen concentration can be reduced to $<1 \%$ (116). Oxygen can produce ATP, a product necessary for cell survival. Through oxidative phosphorylation of mitochondria, cells maintain an adequate supply of ATP. However, under hypoxia, cells promote HIF activation or reduce gene transcription by sensing the change of oxygen tension. Under the premise of insufficient oxygen, the adaptive process is activated to improve cell survival (117).

On the one hand, hypoxia preconditioning enhances the osteogenic differentiation potential of BMSCs $(31,118)$, which could promote bone regeneration (25) and adipogenic differentiation (77). While short-term $(48 \mathrm{~h})$ hypoxic exposure $\left(\begin{array}{ll}1 \% & \mathrm{O}_{2}\end{array}\right)$ suggest decreased osteogenic differentiation after transplantation of BMSCs to a hypoxic microenvironment (103). It was showed that hypoxia reduces osteogenic and adipogenic differentiation of MSCs by inhibiting RUNX2 (41) and HIF-1 $\alpha$ stabilization $(24,118,119)$. It is reported that early hypoxia can accelerate the osteogenesis of BMSCs, however, prolonged hypoxia results in the opposite trend (27). Nevertheless, it was shown that hypoxia culture may not exert effect on the osteogenesis of BMSCs $(120,121)$.

In view of the practical significance of hypoxia in the development and differentiation stage of stem cells, the outcome of stem cell fate and differentiation of research has been underway for more than 20 years. However, due to the differences of cell separation methods, research parameters, growth factors, oxygen concentration and evaluation experimental techniques, the differences between the research results of the role of oxygen in stem cells are highlighted (122). There are still a lot of unknown and exploratory areas in the later research. With the development of transcriptomics and bioinformatics, the behavior of stem cells focuses on epigenetic regulation and modification, and hypoxia has an effect on the epigenetic modification levels of cells. The coexistence of transcription factors suggests the correlation between hypoxia and cell reprogramming related epigenetics. More and more studies have focused on the roles of lncRNAs, circRNAs and miRNAs and their interactions in the regulation of stem cell survival and regeneration under hypoxia. The network could help us better interpret stem cell behavior and provide direction for in vitro modification of stem cells for transplantation.

MSCs can be collected from multiple parts of the oral cavity, such as the dental papilla, dental pulp, periodontal ligament, etc. These stem cells can be used as good tools for bone regeneration and tooth tissue regeneration. Odontogenic stem cells are hypoxic in vivo under both physiological and pathological conditions. The average oxygen partial pressure in the pulp of rat incisors is $23.2 \mathrm{mmHg}$, which is approximately equivalent to $3-12 \%$ oxygen concentration $(116,123,124)$. In some relatively hypoxic tissues or pathological conditions, oxygen concentration is lower, often less than 1\% (116). The pulp is wrapped by the hard dental tissue, and blood oxygen can only reach the pulp cells through the narrow apical orifice, lacking effective collateral circulation. When inflammation or trauma occurs, the vascular nerve bundles of the pulp are easily damaged, resulting in the state of ischemia and hypoxia of the pulp (125). Under the condition of periodontal inflammation, the deeper the periodontal pocket, the lower the oxygen content. The research shows that the average oxygen partial pressure in the deep periodontal pocket is only $1.8 \% \mathrm{O}_{2}$ (126). Hypoxia is a common phenomenon in both pathological and physiological states. Currently, hypoxia-related ncRNAs (lncRNA STL, miR210, IncRNA H19, circRNA CDK8) have been thought to be related to the fate of odontogenic stem cells through different mechanisms. More differentiated ncRNAs induced by hypoxia are worthy of further study and exploration as potential targets.

In addition, oxygen, as a metabolic substrate, can correspondingly reshape cell metabolism. HIF pathway, as a transcription factor, participates in cell metabolism, making it the main contributor to cell response during hypoxia, energy crisis and metabolic disorder. In turn, HIF pathway activity is regulated by various factors, including the supply and utilization of $\mathrm{O}_{2}$ and key metabolic substrates (127129). Hypoxia induced HIF activity initiates a powerful transcriptional program of more than 200 genes. Broadly speaking, the purpose of these adaptations is to increase oxygen delivery or reduce oxygen consumption to meet metabolic needs and normalize local $\mathrm{PO}_{2}$. For example, HIF induction triggers erythropoiesis [erythropoietin (EPO)] and iron homeostasis [e.g., transferrin (TF)] to increase circulating red blood cell (RBC) levels (130, 131). The behavior and differentiation fate of MSCs are closely related to metabolism. As an important substrate of cell metabolism, hypoxia is involved in regulating the behavior and fate of MSCs by affecting ncRNAs, which is worthy of further exploration.

\section{CONCLUSIONS}

As the physiological environment of stem cells, hypoxia also exists in the tumor microenvironment, inflammatory microenvironment and temporary stimulation of some extreme 
organism conditions, which has the function of double-edged sword. The effect of hypoxia on MSCs may be closely related to the duration of treatment, oxygen concentration, and cell state. There are also differences in regulatory mechanisms among different cells. NcRNAs have played a significant role in the modulation of hypoxia on MSCs. Studies of ncRNAs and their interaction can promote or reverse the effects of hypoxia microenvironment on MSCs, and provide good conditions for better modified stem cells for in vivo transplantation.

\section{REFERENCES}

1. Krampera M, Galipeau J, Shi Y, Tarte K, Sensebe L. Immunological characterization of multipotent mesenchymal stromal cells-The International Society for Cellular Therapy (ISCT) working proposal. Cytotherapy. (2013) 15:1054-61. doi: 10.1016/j.jcyt.2013.02.010

2. Galipeau J, Krampera M. The challenge of defining mesenchymal stromal cell potency assays and their potential use as release criteria. Cytotherapy. (2015) 17:125-7. doi: 10.1016/j.jcyt.2014.12.008

3. Almeida-Porada G, Atala AJ, Porada CD. Therapeutic mesenchymal stromal cells for immunotherapy and for gene and drug delivery. Mol Ther Methods Clin Dev. (2020) 16:204-24. doi: 10.1016/j.omtm.2020.01.005

4. Tavakoli S, Ghaderi Jafarbeigloo HR, Shariati A, Jahangiryan A, Jadidi F, Jadidi Kouhbanani MA, et al. Mesenchymal stromal cells; a new horizon in regenerative medicine. J Cell Physiol. (2020) 235:9185210. doi: $10.1002 /$ jcp. 29803

5. Cortés-Hernández LE, Eslami SZ, Alix-Panabières C. Circulating tumor cell as the functional aspect of liquid biopsy to understand the metastatic cascade in solid cancer. Mol Aspects Med. (2020) 72:100816. doi: 10.1016/j.mam.2019.07.008

6. Glassberg MK, Csete I, Simonet E, Elliot SJ. Stem cell therapy for COPD: hope and exploitation. Chest. (2021) 160:127181. doi: 10.1016/j.chest.2021.04.020

7. Pan G, Liu Y, Shang L, Zhou F, Yang S. EMT-associated microRNAs and their roles in cancer stemness and drug resistance. Cancer Commun. (2021) 41:199-217. doi: $10.1002 /$ cac2.12138

8. Galipeau J, Sensébé L. Mesenchymal stromal cells: clinical challenges and therapeutic opportunities. Cell Stem Cell. (2018) 22:824-33. doi: 10.1016/j.stem.2018.05.004

9. Mirzaei H, Sahebkar A, Sichani LS, Moridikia A, Nazari S, Sadri Nahand J, et al. Therapeutic application of multipotent stem cells. J Cell Physiol. (2018) 233:2815-23. doi: 10.1002/jcp. 25990

10. Nikolsky I, Serebrovska TV. Role of hypoxia in stem cell development and functioning. Fiziol Zh. (2009) 55:116-130. doi: 10.1615/IntJPhysPathophys.v1.i1.90

11. Lin Q, Lee YJ, Yun Z. Differentiation arrest by hypoxia. J Biol Chem. (2006) 281:30678-83. doi: 10.1074/jbc.C600120200

12. Murphy MJ. Jr, Lord BI. Hematopoietic stem cell regulation. I. Acute effects of hypoxic-hypoxia on CFU kinetics. Blood. (1973) 42:817. doi: 10.1182/blood.V42.1.81.81

13. Desplat V, Faucher JL, Mahon FX, Dello Sbarba P, Praloran V, Ivanovic Z. Hypoxia modifies proliferation and differentiation of CD34(+) CML cells. Stem Cells. (2002) 20:347-54. doi: 10.1634/stemcells.20-4-347

14. Zhang CP, Zhu LL, Zhao T, Zhao H, Huang X, Ma X, et al. Characteristics of neural stem cells expanded in lowered oxygen and the potential role of hypoxia-inducible factor-1Alpha. Neurosignals. (2006) 15:25965. doi: 10.1159/000103385

15. Meng X, Wielockx B, Rauner M, Bozec A. Hypoxia-inducible factors regulate osteoclasts in health and disease. Front Cell Dev Biol. (2021) 9:658893. doi: 10.3389/fcell.2021.658893

16. McNamee EN, Korns Johnson D, Homann D, Clambey ET. Hypoxia and hypoxia-inducible factors as regulators of $\mathrm{T}$ cell development, differentiation, and function. Immunol Res. (2013) 55:58-70. doi: 10.1007/s12026-012-8349-8

\section{AUTHOR CONTRIBUTIONS}

YY: drafted the manuscript and revised. XZ: collected and integrated data. YX and JY: conceptualization and funding acquisition. All authors read and approved the final manuscript.

\section{FUNDING}

This work was supported by National Natural Science Foundation of China (grant numbers: 81873707 and 81900962).

17. Spencer JA, Ferraro F, Roussakis E, Klein A, Wu J, Runnels JM, et al. Direct measurement of local oxygen concentration in the bone marrow of live animals. Nature. (2014) 508:269-73. doi: 10.1038/nature13034

18. Semenza GL, Wang GL. A nuclear factor induced by hypoxia via de novo protein synthesis binds to the human erythropoietin gene enhancer at a site required for transcriptional activation. Mol Cell Biol. (1992) 12:544754. doi: 10.1128/MCB.12.12.5447

19. Wenger RH, Gassmann M. Oxygen(es) and the hypoxia-inducible factor-1. Biol Chem. (1997) 378:609-16.

20. Loboda A, Jozkowicz A, Dulak J. HIF-1 and HIF-2 transcription factors-similar but not identical. Mol Cells. (2010) 29:43542. doi: $10.1007 / \mathrm{s} 10059-010-0067-2$

21. Mole DR. Iron homeostasis and its interaction with prolyl hydroxylases. Antioxid Redox Signal. (2010) 12:445-58. doi: 10.1089/ars.2009.2790

22. Annabi B, Lee YT, Turcotte S, Naud E, Desrosiers RR, Champagne $\mathrm{M}$, et al. Hypoxia promotes murine bone-marrow-derived stromal cell migration and tube formation. Stem Cells. (2003) 21:337-47. doi: 10.1634/stemcells.21-3-337

23. Aranha AM, Zhang Z, Neiva KG, Costa CA, Hebling J, Nör JE. Hypoxia enhances the angiogenic potential of human dental pulp cells. J Endod. (2010) 36:1633-7. doi: 10.1016/j.joen.2010.05.013

24. Boyette LB, Creasey OA, Guzik L, Lozito T, Tuan RS. Human bone marrow-derived mesenchymal stem cells display enhanced clonogenicity but impaired differentiation with hypoxic preconditioning. Stem Cells Transl Med. (2014) 3:241-54. doi: 10.5966/sctm.2013-0079

25. Ciapetti G, Granchi D, Fotia C, Savarino L, Dallari D, Del Piccolo N, et al. Effects of hypoxia on osteogenic differentiation of mesenchymal stromal cells used as a cell therapy for avascular necrosis of the femoral head. Cytotherapy. (2016) 18:1087-99. doi: 10.1016/j.jcyt.2016.06.005

26. D'Ippolito G, Diabira S, Howard GA, Roos BA, Schiller PC. Low oxygen tension inhibits osteogenic differentiation and enhances stemness of human MIAMI cells. Bone. (2006) 39:513-22. doi: 10.1016/j.bone.2006.02.061

27. Ding $H$, Chen S, Yin JH, Xie XT, Zhu ZH, Gao YS, et al. Continuous hypoxia regulates the osteogenic potential of mesenchymal stem cells in a time-dependent manner. Mol Med Rep. (2014) 10:2184-90. doi: 10.3892/mmr.2014.2451

28. Fujio M, Xing Z, Sharabi N, Xue Y, Yamamoto A, Hibi H, et al. Conditioned media from hypoxic-cultured human dental pulp cells promotes bone healing during distraction osteogenesis. J Tissue Eng Regen Med. (2017) 11:2116-26. doi: 10.1002/term.2109

29. Fink T, Abildtrup L, Fogd K, Abdallah BM, Kassem M, Ebbesen P, et al. Induction of adipocyte-like phenotype in human mesenchymal stem cells by hypoxia. Stem Cells. (2004) 22:1346-55. doi: 10.1634/stemcells.200 4-0038

30. Grayson WL, Zhao F, Bunnell B, Ma T. Hypoxia enhances proliferation and tissue formation of human mesenchymal stem cells. Biochem Biophys Res Commun. (2007) 358:948-53. doi: 10.1016/j.bbrc.2007.05.054

31. Gu Q, Gu Y, Shi Q, Yang H. Hypoxia promotes osteogenesis of human placental-derived mesenchymal stem cells. Tohoku J Exp Med. (2016) 239:287-96. doi: 10.1620/tjem.239.287

32. Holzwarth C, Vaegler M, Gieseke F, Pfister SM, Handgretinger R, Kerst $\mathrm{G}$, et al. Low physiologic oxygen tensions reduce proliferation and differentiation of human multipotent mesenchymal stromal cells. BMC Cell Biol. (2010) 11:11. doi: 10.1186/1471-2121-11-11 
33. Kwon SY, Chun SY, Ha YS, Kim DH, Kim J, Song PH, et al. Hypoxia enhances cell properties of human mesenchymal stem cells. Tissue Eng Regen Med. (2017) 14:595-604. doi: 10.1007/s13770-017-0068-8

34. Lee HH, Chang CC, Shieh MJ, Wang JP, Chen YT, Young TH, et al. Hypoxia enhances chondrogenesis and prevents terminal differentiation through PI3K/Akt/FoxO dependent anti-apoptotic effect. Sci Rep. (2013) 3:2683. doi: $10.1038 /$ srep02683

35. Lennon DP, Edmison JM, Caplan AI. Cultivation of rat marrowderived mesenchymal stem cells in reduced oxygen tension: effects on in vitro and in vivo osteochondrogenesis. J Cell Physiol. (2001) 187:34555. doi: $10.1002 /$ jcp. 1081

36. Li L, Zhu YQ, Jiang L, Peng W, Ritchie HH. Hypoxia promotes mineralization of human dental pulp cells. J Endod. (2011) 37:799802. doi: $10.1016 /$ j.joen.2011.02.028

37. Robins JC, Akeno N, Mukherjee A, Dalal RR, Aronow BJ, Koopman P, et al. Hypoxia induces chondrocyte-specific gene expression in mesenchymal cells in association with transcriptional activation of Sox9. Bone. (2005) 37:313-22. doi: 10.1016/j.bone.2005.04.040

38. Vanacker J, Viswanath A, De Berdt P, Everard A, Cani PD, Bouzin C, et al. Hypoxia modulates the differentiation potential of stem cells of the apical papilla. J Endod. (2014) 40:1410-8. doi: 10.1016/j.joen.2014.04.008

39. Wu Y, Yang Y, Yang P, Gu Y, Zhao Z, Tan L, et al. The osteogenic differentiation of PDLSCs is mediated through MEK/ERK and p38 MAPK signalling under hypoxia. Arch Oral Biol. (2013) 58:135768. doi: 10.1016/j.archoralbio.2013.03.011

40. Xu W, Xu R, Li Z, Wang Y, Hu R. Hypoxia changes chemotaxis behaviour of mesenchymal stem cells via HIF-1 $\alpha$ signalling. J Cell Mol Med. (2019) 23:1899-907. doi: $10.1111 / \mathrm{jcmm} .14091$

41. Zhang P, Ha N, Dai Q, Zhou S, Yu C, Jiang L. Hypoxia suppresses osteogenesis of bone mesenchymal stem cells via the extracellular signalregulated $1 / 2$ and $\mathrm{p} 38$-mitogen activated protein kinase signaling pathways. Mol Med Rep. (2017) 16:5515-22. doi: 10.3892/mmr.2017.7276

42. Zhang QB, Zhang ZQ, Fang SL, Liu YR, Jiang G, Li KF. Effects of hypoxia on proliferation and osteogenic differentiation of periodontal ligament stem cells: an in vitro and in vivo study. Genet Mol Res. (2014) 13:1020414. doi: 10.4238/2014.December.4.15

43. Wang Y, Wan C, Deng L, Liu X, Cao X, Gilbert SR, et al. The hypoxia-inducible factor alpha pathway couples angiogenesis to osteogenesis during skeletal development. J Clin Invest. (2007) 117:1616-26. doi: 10.1172/JCI31581

44. Hu YY, Fu LA, Li SZ, Chen Y, Li JC, Han J, et al. Hif- $1 \alpha$ and Hif- $2 \alpha$ differentially regulate Notch signaling through competitive interaction with the intracellular domain of Notch receptors in glioma stem cells. Cancer Lett. (2014) 349:67-76. doi: 10.1016/j.canlet.2014.03.035

45. Rankin EB, Giaccia AJ, Schipani E. A central role for hypoxic signaling in cartilage, bone, and hematopoiesis. Curr Osteoporos Rep. (2011) 9:4652. doi: 10.1007/s11914-011-0047-2

46. Muz B, de la Puente P, Azab F, Azab AK. The role of hypoxia in cancer progression, angiogenesis, metastasis, and resistance to therapy. Hypoxia. (2015) 3:83-92. doi: 10.2147/HP.S93413

47. Scully D, Keane E, Batt E, Karunakaran P, Higgins DF, Itasaki N. Hypoxia promotes production of neural crest cells in the embryonic head. Development. (2016) 143:1742-52. doi: 10.1242/dev.131912

48. Nakamura N, Shi X, Darabi R, Li Y. Hypoxia in cell reprogramming and the epigenetic regulations. Front Cell Dev Biol. (2021) 9:609984. doi: $10.3389 /$ fcell.2021.609984

49. Li J, Liu C. Coding or noncoding, the converging concepts of RNAs. Front Genet. (2019) 10:496. doi: 10.3389/fgene.2019.00496

50. Ponjavic J, Ponting CP, Lunter G. Functionality or transcriptional noise? Evidence for selection within long noncoding RNAs. Genome Res. (2007) 17:556-65. doi: 10.1101/gr.6036807

51. Cech TR, Steitz JA. The noncoding RNA revolution-trashing old rules to forge new ones. Cell. (2014) 157:77-94. doi: 10.1016/j.cell.2014.03.008

52. Peschansky VJ, Wahlestedt C. Non-coding RNAs as direct and indirect modulators of epigenetic regulation. Epigenetics. (2014) 9:3-12. doi: 10.4161/epi.27473

53. Zhang $\mathrm{P}, \mathrm{Wu} \mathrm{W}$, Chen $\mathrm{Q}$, Chen M. Non-coding RNAs and their integrated networks. J Integr Bioinform. (2019) 16:20190027. doi: 10.1515/jib-2019-0027
54. Ha M, Kim VN. Regulation of microRNA biogenesis. Nat Rev Mol Cell Biol. (2014) 15:509-24. doi: 10.1038/nrm3838

55. Reinhart BJ, Slack FJ, Basson M, Pasquinelli AE, Bettinger JC, Rougvie $\mathrm{AE}$, et al. The 21-nucleotide let-7 RNA regulates developmental timing in Caenorhabditis elegans. Nature. (2000) 403:901-6. doi: 10.1038/35002607

56. Lagos-Quintana M, Rauhut R, Lendeckel W, Tuschl T. Identification of novel genes coding for small expressed RNAs. Science. (2001) 294:8538. doi: 10.1126/science. 1064921

57. Camps C, Saini HK, Mole DR, Choudhry H, Reczko M, Guerra-Assunção JA, et al. Integrated analysis of microRNA and mRNA expression and association with HIF binding reveals the complexity of microRNA expression regulation under hypoxia. Mol Cancer. (2014) 13:28. doi: 10.1186/1476-4598-13-28

58. Ma L, Bajic VB, Zhang Z. On the classification of long non-coding RNAs. RNA Biol. (2013) 10:925-33. doi: 10.4161/rna.24604

59. Slemc L, Kunej T. Transcription factor HIF1A: downstream targets, associated pathways, polymorphic hypoxia response element (HRE) sites, and initiative for standardization of reporting in scientific literature. Tumour Biol. (2016) 37:14851-61. doi: 10.1007/s13277-016-5331-4

60. Choudhry H, Schödel J, Oikonomopoulos S, Camps C, Grampp S, Harris $\mathrm{AL}$, et al. Extensive regulation of the non-coding transcriptome by hypoxia: role of HIF in releasing paused RNApol2. EMBO Rep. (2014) 15:706. doi: $10.1002 / \mathrm{embr} .201337642$

61. Salzman J, Gawad C, Wang PL, Lacayo N, Brown PO. Circular RNAs are the predominant transcript isoform from hundreds of human genes in diverse cell types. PLoS ONE. (2012) 7:e30733. doi: 10.1371/journal.pone.0030733

62. Salzman J. Circular RNA expression: its potential regulation and function. Trends Genet. (2016) 32:309-16. doi: 10.1016/j.tig.2016.03.002

63. Vo JN, Cieslik M, Zhang Y, Shukla S, Xiao L, Zhang Y, et al. The landscape of circular RNA in cancer. Cell. (2019) 176:869-81.e813. doi: 10.1016/j.cell.2018.12.021

64. Jeck WR, Sorrentino JA, Wang K, Slevin MK, Burd CE, Liu J, et al. Circular RNAs are abundant, conserved, and associated with ALU repeats. RNA. (2013) 19:141-57. doi: 10.1261/rna.035667.112

65. Ye CY, Chen L, Liu C, Zhu QH, Fan L. Widespread noncoding circular RNAs in plants. New Phytol. (2015) 208:88-95. doi: 10.1111/nph.13585

66. Huang M, Zhong Z, Lv M, Shu J, Tian Q, Chen J. Comprehensive analysis of differentially expressed profiles of IncRNAs and circRNAs with associated coexpression and ceRNA networks in bladder carcinoma. Oncotarget. (2016) 7:47186-200. doi: 10.18632/oncotarget.9706

67. Sun X, Liu J, Xu C, Tang SC, Ren H. The insights of Let-7 miRNAs in oncogenesis and stem cell potency. J Cell Mol Med. (2016) 20:177988. doi: $10.1111 / \mathrm{jcmm} .12861$

68. De Bels D, Corazza F, Balestra C. Oxygen sensing, homeostasis, and disease. $N$ Engl $J$ Med. (2011) 365:1845; author reply 1846. doi: 10.1056/NEJMc1110602

69. Barreca MM, Zichittella C, Alessandro R, Conigliaro A. Hypoxia-induced non-coding RNAs controlling cell viability in cancer. Int J Mol Sci. (2021) 22:1857. doi: 10.3390/ijms22041857

70. Choong OK, Chen CY, Zhang J, Lin JH, Lin PJ, Ruan SC, et al. Hypoxiainduced H19/YB-1 cascade modulates cardiac remodeling after infarction. Theranostics. (2019) 9:6550-67. doi: 10.7150/thno.35218

71. Mineo M, Ricklefs F, Rooj AK, Lyons SM, Ivanov P, Ansari KI, et al. The long non-coding RNA HIF1A-AS2 facilitates the maintenance of mesenchymal glioblastoma stem-like cells in hypoxic niches. Cell Rep. (2016) 15:25009. doi: 10.1016/j.celrep.2016.05.018

72. Dell'Aversana C, Cuomo F, Botti C, Maione C, Carissimo A, Casamassimi A, et al. Hypoxia-regulated miRNAs in human mesenchymal stem cells: exploring the regulatory effects in ischemic disorders. Int J Mol Sci. (2019) 20:1340. doi: 10.3390/ijms200 61340

73. Devlin C, Greco S, Martelli F, Ivan M. miR-210: more than a silent player in hypoxia. IUBMB Life. (2011) 63:94-100. doi: 10.1002/iub.427

74. Shi R, Yang H, Lin X, Cao Y, Zhang C, Fan Z, et al. Analysis of the characteristics and expression profiles of coding and noncoding RNAs of human dental pulp stem cells in hypoxic conditions. Stem Cell Res Ther. (2019) 10:89. doi: 10.1186/s13287-019-1192-2

75. Sun $\mathrm{X}$, Jin $\mathrm{Y}$, Liang $\mathrm{Q}$, Tang J, Chen J, Yu Q, et al. Altered expression of circular RNAs in human placental chorionic plate-derived 
mesenchymal stem cells pretreated with hypoxia. J Clin Lab Anal. (2019) 33:e22825. doi: 10.1002/jcla.22825

76. Grayson WL, Zhao F, Izadpanah R, Bunnell B, Ma T. Effects of hypoxia on human mesenchymal stem cell expansion and plasticity in 3D constructs. $J$ Cell Physiol. (2006) 207:331-9. doi: 10.1002/jcp.20571

77. Ren H, Cao Y, Zhao Q, Li J, Zhou C, Liao L, et al. Proliferation and differentiation of bone marrow stromal cells under hypoxic conditions. Biochem Biophys Res Commun. (2006) 347:12-21. doi: 10.1016/j.bbrc.2006.05.169

78. Martin-Rendon E, Hale SJ, Ryan D, Baban D, Forde SP, Roubelakis M, et al. Transcriptional profiling of human cord blood CD133+ and cultured bone marrow mesenchymal stem cells in response to hypoxia. Stem Cells. (2007) 25:1003-12. doi: 10.1634/stemcells.2006-0398

79. Meng SS, Xu XP, Chang W, Lu ZH, Huang LL, Xu JY, et al. LincRNA-p21 promotes mesenchymal stem cell migration capacity and survival through hypoxic preconditioning. Stem Cell Res Ther. (2018) 9:280. doi: 10.1186/s13287-018-1031-x

80. Chen W, Zhuo Y, Duan D, Lu M. Effects of hypoxia on differentiation of mesenchymal stem cells. Curr Stem Cell Res Ther. (2020) 15:3329. doi: 10.2174/1574888X14666190823144928

81. Xing J, Ying Y, Mao C, Liu Y, Wang T, Zhao Q, et al. Hypoxia induces senescence of bone marrow mesenchymal stem cells via altered gut microbiota. Nat Commun. (2018) 9:2020. doi: 10.1038/s41467-018-04453-9

82. Tsai CC, Chen YJ, Yew TL, Chen LL, Wang JY, Chiu CH, et al. Hypoxia inhibits senescence and maintains mesenchymal stem cell properties through down-regulation of E2A-p21 by HIF-TWIST. Blood. (2011) 117:45969. doi: 10.1182/blood-2010-05-287508

83. Korski KI, Kubli DA, Wang BJ, Khalafalla FG, Monsanto MM, Firouzi F, et al. Hypoxia prevents mitochondrial dysfunction and senescence in human c-Kit $(+)$ cardiac progenitor cells. Stem Cells. (2019) 37:55567. doi: $10.1002 /$ stem. 2970

84. Liu J, He J, Ge L, Xiao H, Huang Y, Zeng L, et al. Hypoxic preconditioning rejuvenates mesenchymal stem cells and enhances neuroprotection following intracerebral hemorrhage via the miR-326-mediated autophagy. Stem Cell Res Ther. (2021) 12:413. doi: 10.1186/s13287-021-02480-w

85. Sun J, Wei ZZ, Gu X, Zhang JY, Zhang Y, Li J, et al. Intranasal delivery of hypoxia-preconditioned bone marrow-derived mesenchymal stem cells enhanced regenerative effects after intracerebral hemorrhagic stroke in mice. Exp Neurol. (2015) 272:78-87. doi: 10.1016/j.expneurol.2015.03.011

86. Wakai T, Narasimhan P, Sakata H, Wang E, Yoshioka H, Kinouchi H, et al. Hypoxic preconditioning enhances neural stem cell transplantation therapy after intracerebral hemorrhage in mice. J Cereb Blood Flow Metab. (2016) 36:2134-45. doi: 10.1177/0271678X15613798

87. Iida K, Takeda-Kawaguchi T, Tezuka Y, Kunisada T, Shibata T, Tezuka $\mathrm{K}$. Hypoxia enhances colony formation and proliferation but inhibits differentiation of human dental pulp cells. Arch Oral Biol. (2010) 55:64854. doi: 10.1016/j.archoralbio.2010.06.005

88. Zhou Y, Fan W, Xiao Y. The effect of hypoxia on the stemness and differentiation capacity of PDLC and DPC. Biomed Res Int. (2014) 2014:890675. doi: 10.1155/2014/890675

89. Zhang HY, Liu R, Xing YJ, Xu P, Li Y, Li CJ. Effects of hypoxia on the proliferation, mineralization and ultrastructure of human periodontal ligament fibroblasts in vitro. Exp Ther Med. (2013) 6:1553-9. doi: 10.3892/etm.2013.1349

90. Hou J, Wang L, Wu Q, Zheng G, Long $\mathrm{H}, \mathrm{Wu} \mathrm{H}$, et al. Long noncoding RNA H19 upregulates vascular endothelial growth factor A to enhance mesenchymal stem cells survival and angiogenic capacity by inhibiting miR199a-5p. Stem Cell Res Ther. (2018) 9:109. doi: 10.1186/s13287-018-0861-x

91. Chang W, Lee CY, Park JH, Park MS, Maeng LS, Yoon CS, et al. Survival of hypoxic human mesenchymal stem cells is enhanced by a positive feedback loop involving miR-210 and hypoxia-inducible factor 1. J Vet Sci. (2013) 14:69-76. doi: 10.4142/jvs.2013.14.1.69

92. Sun L, Zhu W, Zhao P, Wang Q, Fan B, Zhu Y, et al. Long noncoding RNA UCA1 from hypoxia-conditioned hMSC-derived exosomes: a novel molecular target for cardioprotection through miR-873-5p/XIAP axis. Cell Death Dis. (2020) 11:696. doi: 10.1038/s41419-020-02783-5

93. Yang C, Liu X, Zhao K, Zhu Y, Hu B, Zhou Y, et al. miRNA21 promotes osteogenesis via the PTEN/PI3K/Akt/HIF-1 $\alpha$ pathway and enhances bone regeneration in critical size defects. Stem Cell Res Ther. (2019) 10:65. doi: 10.1186/s13287-019-1168-2

94. Zheng J, Zhu X, He Y, Hou S, Liu T, Zhi K, et al. CircCDK8 regulates osteogenic differentiation and apoptosis of PDLSCs by inducing ER stress/autophagy during hypoxia. Ann N Y Acad Sci. (2021) 1485:5670. doi: 10.1111 /nyas.14483

95. Zhou X, Xu W, Wang Y, Zhang H, Zhang L, Li C, et al. LncRNA DNM3OS regulates GREM2 via miR-127-5p to suppress early chondrogenic differentiation of rat mesenchymal stem cells under hypoxic conditions. Cell Mol Biol Lett. (2021) 26:22. doi: 10.1186/s11658-021-00269-6

96. Kim HW, Haider HK, Jiang S, Ashraf M. Ischemic preconditioning augments survival of stem cells via miR-210 expression by targeting caspase-8-associated protein 2. J Biol Chem. (2009) 284:33161-8. doi: 10.1074/jbc.M109.020925

97. Wang L, Xu B, Sun S, Wang B. Overexpression of long noncoding RNA H19 relieves hypoxia-induced injury by downregulating microRNA-107 in neural stem cells. Neurosci Lett. (2021) 753:135855. doi: 10.1016/j.neulet.2021.135855

98. Chan YC, Banerjee J, Choi SY, Sen CK. miR-210: the master hypoxamir. Microcirculation. (2012) 19:215-23. doi: 10.1111/j.1549-8719.2011.00154.x

99. Jin W, Liang X, Brooks A, Futrega K, Liu X, Doran MR, et al. Modelling of the SDF-1/CXCR4 regulated in vivo homing of therapeutic mesenchymal stem/stromal cells in mice. PeerJ. (2018) 6:e6072. doi: 10.7717/peerj.6072

100. Werle SB, Chagastelles P, Pranke P, Casagrande L. Hypoxia upregulates the expression of the pluripotency markers in the stem cells from human deciduous teeth. Clin Oral Investig. (2019) 23:199-207. doi: 10.1007/s00784-018-2427-9

101. Fehrer C, Brunauer R, Laschober G, Unterluggauer H, Reitinger S, Kloss F, et al. Reduced oxygen tension attenuates differentiation capacity of human mesenchymal stem cells and prolongs their lifespan. Aging Cell. (2007) 6:745-57. doi: 10.1111/j.1474-9726.2007.00336.x

102. D’Ippolito G, Diabira S, Howard GA, Menei P, Roos BA, Schiller PC. Marrow-isolated adult multilineage inducible (MIAMI) cells, a unique population of postnatal young and old human cells with extensive expansion and differentiation potential. J Cell Sci. (2004) 117:297181. doi: $10.1242 /$ jcs. 01103

103. Potier E, Ferreira E, Andriamanalijaona R, Pujol JP, Oudina K, LogeartAvramoglou D, et al. Hypoxia affects mesenchymal stromal cell osteogenic differentiation and angiogenic factor expression. Bone. (2007) 40:107887. doi: 10.1016/j.bone.2006.11.024

104. Mizuno Y, Tokuzawa Y, Ninomiya Y, Yagi K, Yatsuka-Kanesaki Y, Suda $\mathrm{T}$, et al. miR-210 promotes osteoblastic differentiation through inhibition of AcvR1b. FEBS Lett. (2009) 583:2263-8. doi: 10.1016/j.febslet.2009. 06.006

105. Singh RP, Franke K, Wielockx B. Hypoxia-mediated regulation of stem cell fate. High Alt Med Biol. (2012) 13:162-8. doi: 10.1089/ham.201 2.1043

106. Semenza GL. Regulation of mammalian O2 homeostasis by hypoxia-inducible factor 1. Annu Rev Cell Dev Biol. (1999) 15:551-78. doi: 10.1146/annurev.cellbio.15.1.551

107. Liu L, Simon MC. Regulation of transcription and translation by hypoxia. Cancer Biol Ther. (2004) 3:492-7. doi: 10.4161/cbt.3. 6.1010

108. Wang DW, Fermor B, Gimble JM, Awad HA, Guilak F. Influence of oxygen on the proliferation and metabolism of adipose derived adult stem cells. J Cell Physiol. (2005) 204:184-91. doi: 10.1002/jcp. 20324

109. Simon MC, Keith B. The role of oxygen availability in embryonic development and stem cell function. Nat Rev Mol Cell Biol. (2008) 9:28596. doi: $10.1038 / \mathrm{nrm} 2354$

110. Ezashi T, Das P, Roberts RM. Low O2 tensions and the prevention of differentiation of hES cells. Proc Natl Acad Sci USA. (2005) 102:47838. doi: 10.1073/pnas.0501283102

111. Shyh-Chang N, Zhu H, Yvanka de Soysa T, Shinoda G, Seligson MT, Tsanov KM, et al. Lin28 enhances tissue repair by reprogramming cellular metabolism. Cell. (2013) 155:778-92. doi: 10.1016/j.cell.2013.09.059

112. Mosteiro L, Pantoja C, Alcazar N, Marión RM, Chondronasiou $D$, Rovira $M$, et al. Tissue damage and senescence provide 
critical signals for cellular reprogramming in vivo. Science. (2016) 354:aaf4445. doi: 10.1126/science.aaf4445

113. Fang L, El Wazan L, Tan C, Nguyen T, Hung SSC, Hewitt AW, et al. Potentials of cellular reprogramming as a novel strategy for neuroregeneration. Front Cell Neurosci. (2018) 12:460. doi: 10.3389/fncel.2018.00460

114. Huels DJ, Medema JP. Think about the environment: cellular reprogramming by the extracellular matrix. Cell Stem Cell. (2018) 22:7-9. doi: 10.1016/j.stem.2017.12.006

115. Yui S, Azzolin L, Maimets M, Pedersen MT, Fordham RP, Hansen SL, et al. YAP/TAZ-dependent reprogramming of colonic epithelium links ECM remodeling to tissue regeneration. Cell Stem Cell. (2018) 22:3549.e37. doi: 10.1016/j.stem.2017.11.001

116. Mohyeldin A, Garzón-Muvdi T, Quiñones-Hinojosa A. Oxygen in stem cell biology: a critical component of the stem cell niche. Cell Stem Cell. (2010) 7:150-61. doi: 10.1016/j.stem.2010.07.007

117. Guzy RD, Schumacker PT. Oxygen sensing by mitochondria at complex III: the paradox of increased reactive oxygen species during hypoxia. Exp Physiol. (2006) 91:807-19. doi: 10.1113/expphysiol.2006.033506

118. Yoo $\mathrm{HI}$, Moon $\mathrm{YH}, \mathrm{Kim} \mathrm{MS}$. Effects of $\mathrm{CoCl} 2$ on multi-lineage differentiation of C3H/10T1/2 mesenchymal stem cells. Korean J Physiol Pharmacol. (2016) 20:53-62. doi: 10.4196/kjpp.2016.20.1.53

119. Park IH, Kim KH, Choi HK, Shim JS, Whang SY, Hahn SJ, et al. Constitutive stabilization of hypoxia-inducible factor alpha selectively promotes the self-renewal of mesenchymal progenitors and maintains mesenchymal stromal cells in an undifferentiated state. Exp Mol Med. (2013) 45:e44. doi: 10.1038/emm.2013.87

120. Han YS, Lee JH, Yoon YM, Yun CW, Noh H, Lee SH. Hypoxiainduced expression of cellular prion protein improves the therapeutic potential of mesenchymal stem cells. Cell Death Dis. (2016) 7:e2395. doi: 10.1038/cddis.2016.310

121. Elabd C, Ichim TE, Miller K, Anneling A, Grinstein V, Vargas V, et al. Comparing atmospheric and hypoxic cultured mesenchymal stem cell transcriptome: implication for stem cell therapies targeting intervertebral discs. J Transl Med. (2018) 16:222. doi: 10.1186/s12967-018-1601-9

122. Ma T, Grayson WL, Fröhlich M, Vunjak-Novakovic G. Hypoxia and stem cell-based engineering of mesenchymal tissues. Biotechnol Prog. (2009) 25:32-42. doi: 10.1002/btpr.128

123. Yu CY, Boyd NM, Cringle SJ, Alder VA, Yu DY. Oxygen distribution and consumption in rat lower incisor pulp. Arch Oral Biol. (2002) 47:52936. doi: 10.1016/S0003-9969(02)00036-5

124. Agata H, Sumita Y, Asahina I, Tojo A, Kagami H. Ischemic culture of dental pulp-derived cells is a useful model in which to investigate mechanisms of post-ischemic tissue recovery. Histol Histopathol. (2013) 28:985-91. doi: 10.14670/HH-28.985
125. Agata $\mathrm{H}$, Kagami $\mathrm{H}$, Watanabe $\mathrm{N}$, Ueda $\mathrm{M}$. Effect of ischemic culture conditions on the survival and differentiation of porcine dental pulp-derived cells. Differentiation. (2008) 76:981-93. doi: 10.1111/j.1432-0436.2008.00282.x

126. Mettraux GR, Gusberti FA, Graf H. Oxygen tension (pO2) in untreated human periodontal pockets. J Periodontol. (1984) 55:516-21. doi: 10.1902/jop.1984.55.9.516

127. Kwon SJ, Lee YJ. Effect of low glutamine/glucose on hypoxia-induced elevation of hypoxia-inducible factor-1alpha in human pancreatic cancer MiaPaCa-2 and human prostatic cancer DU-145 cells. Clin Cancer Res. (2005) 11:4694-700. doi: 10.1158/1078-0432.CCR-04-2530

128. Vordermark D, Kraft P, Katzer A, Bölling T, Willner J, Flentje M. Glucose requirement for hypoxic accumulation of hypoxiainducible factor-1alpha (HIF-1alpha). Cancer Lett. (2005) 230:122-33. doi: 10.1016/j.canlet.2004.12.040

129. Drogat B, Bouchecareilh $M$, North S, Petibois C, Déléris G, Chevet E, et al. Acute L-glutamine deprivation compromises VEGF-a upregulation in A549/8 human carcinoma cells. J Cell Physiol. (2007) 212:463-72. doi: 10.1002/jcp. 21044

130. Shah YM, Xie L. Hypoxia-inducible factors link iron homeostasis and erythropoiesis. Gastroenterology. (2014) 146:63042. doi: 10.1053/j.gastro.2013.12.031

131. Tang F, Feng L, Li R, Wang W, Liu H, Yang Q, et al. Inhibition of suicidal erythrocyte death by chronic hypoxia. High Alt Med Biol. (2019) 20:1129. doi: 10.1089/ham.2017.0159

Conflict of Interest: The authors declare that the research was conducted in the absence of any commercial or financial relationships that could be construed as a potential conflict of interest.

Publisher's Note: All claims expressed in this article are solely those of the authors and do not necessarily represent those of their affiliated organizations, or those of the publisher, the editors and the reviewers. Any product that may be evaluated in this article, or claim that may be made by its manufacturer, is not guaranteed or endorsed by the publisher.

Copyright (c) $2021 \mathrm{Ye}, \mathrm{Zhao}, \mathrm{Xu}$ and Yu. This is an open-access article distributed under the terms of the Creative Commons Attribution License (CC BY). The use, distribution or reproduction in other forums is permitted, provided the original author(s) and the copyright owner(s) are credited and that the original publication in this journal is cited, in accordance with accepted academic practice. No use, distribution or reproduction is permitted which does not comply with these terms. 